\title{
Narrativas e amazonialismo: representações da Amazônia nos relatos de viagens de Paul Walle
}

\author{
Narratives and Amazonialism: \\ Representations of the Amazon in Paul Walle
}

Francisco Bento da Silva*

Gerson Rodrigues de Albuquerque ${ }^{* *}$

\section{Resumo}

$\mathrm{O}$ artigo discute o modo como o viajante francês Paul Walle narra a Amazônia brasileira, seus habitantes e suas culturas. Interessa destacar que, em narrativas publicadas no início do século XX, Walle adota posturas baseadas em valores eurocêntricos ancorados em pressupostos de superioridade racial, moral, cultural e econômica em voga no contexto temporal de seus escritos. No que tange à dimensão analítica, o foco do artigo está voltado para problematizar o olhar e colocar em evidência as representações, modos de sentir e ver narrados por Walle, tendo como referência as formulações teóricas dos estudos culturais, com destaque para a noção cunhada por Stuart Hall de que "os sistemas de representação são os sistemas de significado pelos quais representamos o mundo para nós mesmos

\section{Abstract}

This article aims to discuss how the French traveler Paul Walle narrates the Brazilian Amazon, its inhabitants and its cultures. At the beginning of the 20th century, Walle's reports were written based on Eurocentric principles anchored in assumptions of racial, moral, cultural and economic superiority. The focus of the article is on the problematization of Walle's 'look' upon the Amazon region, considering the theoretical formulations of the Cultural Studies with emphasis on the Stuart Hall's perspective in which "systems of representation are the systems of meaning by which we represent the world to ourselves and to others." Also, the article takes into account some authors that enable to reflect on colonial/decolonial relations

\footnotetext{
* Universidade Federal do Acre (Ufac), Centro de Filosofia e Ciências Humanas/História (CFCH) e Programa de Pós-Graduação em Letras: Linguagem e identidade (PPGLI), Rio Branco, AC, Brasil. chicobento_ac@yahoo.com.br <https://orcid.org/0000-0002-6611-5391>

** Universidade Federal do Acre (Ufac), Centro de Educação, Letras e Artes (CELA), Programa de Pós-Graduação em Letras: Linguagem e identidade (PPGLI), Rio Branco, AC, Brasil. gerson.ufac@gmail. com <https://orcid.org/0000-0002-8808-6683>
} 
e para os outros". O diálogo com abordagens presentes em vários autores permite refletir sobre as relações coloniais/decoloniais em contextos "latino" americanos e amazônicos.

Palavras-chave: Paul Walle; relatos de viagem; imaginários; Amazônia. in 'Latin' American and Amazonian contexts.

Keywords: Paul Walle; travel reports; imaginary; Amazon.

[...] é o suposto atraso da América que, em primeiro lugar, legitima as intervenções da vanguarda capitalista. Ideologicamente, a tarefa da vanguarda capitalista é a de reinventar uma América como atrasada e negligenciada, de forma a enquadrar seus cenários e sociedades não capitalistas como manifestadamente carentes da exploração racionalizada trazida pelos europeus.

Mary Louise Pratt, 1999, p. 262

Desde a sua inserção na lógica capitalista e colonial, a região que genericamente é chamada de América Latina, tão plural e polissêmica em sentidos culturais, étnicos, econômicos, linguísticos e políticos, foi e ainda é palco de narrativas hegemônicas marcadas pelo prisma da visão colonizadora. Ela é comumente traduzida pelos sujeitos coletivos e individuais, metropolitanos ou periféricos, que se expressam em relação a esse amplo espaço com as marcas idiossincráticas do eurocentrismo científico, racial, político, religioso e cultural. Variados estudos discutem as narrativas da conquista, os discursos da colonização e a invenção do outro coisificado ou apresentado como alteridade inferior e subalterna até os dias atuais. Para esta discussão e abordagem, temos como referencial de análise autores que lidam com a temática da cultura e dessas ideias sedimentadas sobre os espaços e as gentes diversas do "Novo Mundo/América Latina/Amazônia". ${ }^{1}$ Para dialogar com as questões trazidas nos textos de Paul Walle aqui apresentados, partimos dos estudos desenvolvidos por Mary Louise Pratt, Olhos do império (Pratt, 1999); Tzvetan Todorov, A conquista da América (Todorov, 2014); Christian Kiening, O sujeito selvagem (Kiening, 2014); Albert Memmi, Retrato do colonizado precedido pelo retrato do colonizador (Memmi, 1967); Walter Mignolo, La idea de America Latina (Mignolo, 2007), e Ana Pizarro, com Amazônia: as vozes do rio (Pizarro, 2012). 
Todorov afirma que os conquistadores inaugurais e seus predecessores geralmente não estavam em busca de novas verdades, mas procurando "confirmações para uma verdade conhecida de antemão” (Todorov, 2014, p. 27). A conquista, como bem aponta esse autor, será marcada pelo discurso da diferença, que redunda em narrativas, ações e sentimentos de superioridade por parte dos conquistadores desde os primeiros contatos inaugurais. Tais procedimentos iniciados nos primeiros séculos coloniais no narrado Novo Mundo tiveram sobrevida mesmo depois dos processos de independência, ocorridos no século XIX em todo continente americano, pois o colonialismo dará origem à colonialidade com a qual as elites locais mantêm os valores eurocêntricos para exercerem domínio, hegemonia e "consenso".

Os viajantes do período pós-independências e dos primeiros anos do século XX se enquadram, em nosso entender, no que Mary Louise Pratt (1999) vai designar como representantes da vanguarda capitalista. Desse modo, como destacado na epígrafe deste texto, continuamente são reforçadas as narrativas das ausências, dos descompassos, dos atrasos e da necessidade de adesão aos modelos oferecidos como caminhos da ascensão e redenção dos povos "atrasados” à modernidade. Para Pratt, aí se configura a anticonquista, marcada pelo discurso aparentemente neutro do viajante que se vê como pacífico e reflexivo nas suas andanças pelos espaços coloniais.

Acompanhando essa perspectiva, o ensaísta franco-tunisiano Albert Memmi aponta a profusão de narrativas sobre "situações de carência", que mistificam e desumanizam o colonizado e se renovam "pelas exigências históricas, econômicas e culturais do colonizador” (Memmi, 1967, p. 86). Embora esse autor parta da realidade colonial conduzida pela França no século XX, seu estudo pode contribuir para pensar de maneira mais ampla os contextos de dominação mais fluida, sem posse territorial do espaço colonial. Por exemplo, de como ideologicamente o retrato do colonizador se impõe sobre o retrato do colonizado, destituindo-se este último da capacidade de autonomia em relação a sua identidade, sua cultura e sua humanidade, que passam a ser refletidas por outros espelhos em discursos de origens exógenas.

Para Walter Mignolo (2007), foi a história colonial moderna que deu forma e plasmou a ideia de América Latina, de continente americano. Para esse autor, "el continente americano existe sólo como una consecuencia de la expansión colonial europea y los relatos de esa expansión desde el punto de vista europeo, es decir, la perspectiva de la modernidad" (Mignolo, 2007, p. 15). Assim, traçar uma arqueologia da ideia de América Latina permitiria compreender como se fundou a ordem mundial moderna marcada pela 
colonialidade daquilo que o pensamento hegemônico irá chamar de países periféricos.

Na obra de Christian Kiening (2014), O sujeito selvagem: pequena poética do Novo Mundo, temos uma abordagem que busca enfocar os escritos e as obras pictóricas sobre o chamado Novo Mundo, procurando compreender distintas concepções estéticas e narrativas que vão se consolidando pelo olhar do sujeito europeu/eurocêntrico. $\mathrm{O}$ autor não toma esses diversos textos como expressão dos "fatos históricos", mas como escritos marcados pela tônica da diferença e da oscilação (variação e incerteza) que adquirem lugar privilegiado nos múltiplos discursos do e sobre o Novo Mundo: neles, há sempre a marca da retórica da inovação, das viagens espetaculares e dos textos sensacionalistas onde tudo está intimamente relacionado (Kiening, 2014, p. 31).

Nessa mesma linha de abordagem crítica e olhando para a Pan-Amazônia ${ }^{2}$ - principalmente sua dimensão brasileira -, Gerson Albuquerque problematiza o neologismo amazonialismo, que seria marcado por uma miríade de:

"conhecimentos" ou narrativas que inventa, descreve, classifica, cataloga, analisa de forma supostamente objetiva e mesmo científica a "Amazônia", produzindo-a como um lugar no mundo da expansão dos impérios e do imperialismo: uma "Amazônia" ou a "Amazônia", grafada pela escrita de distintos viajantes desde o advento da "modernidade" [...] inventando e catalogando seus povos, rios, fauna e flora, fabricando identidades e fronteiras "amazônicas" e "não amazônicas", fabricando e introjetando narrativas de diferentes sujeitos (pessoas físicas e jurídicas) que partem da ideia ou da palavra/conceito Amazônia como um todo homogêneo, referência de lugar, identidade, vivência ou existência de incontáveis seres humanos e não humanos, naturais e não naturais. (Albuquerque, 2016, p. 77)

Nessa direção, é possível enfatizar que os escritos de Paul Walle se enquadram no rol das narrativas amazonialistas, da conquista da "América" e de invenção do "Novo Mundo" produzidas por vozes comprometidas - intencionalmente ou não - com a lógica linear de tempo e dos binarismos que (des) qualificam e hierarquizam povos, lugares, crenças, modos de vida e natureza.

\section{Paul WAlle: o discurso da anticonquista E DA VANGUARDA CAPITALISTA}

Acompanhando proposições analíticas dos autores anteriormente elencados, tratamos de abordar os escritos de Paul Walle (1872-1950), um viajante 
pouco conhecido no Brasil que, além de geógrafo, explorador e naturalista, foi funcionário do Ministério do Comércio Exterior de seu país e membro da Sociedade de Geografia Comercial de Paris. Nessa função, realizou suas andanças pela América do Sul a partir da última década do século XIX, quando empreendeu missões diplomáticas e comerciais na Argentina, no Paraguai e na Bolívia. Posteriormente, entre 1908 e 1910, fez visitas semelhantes ao Brasil, percorrendo vários estados das atuais regiões Sudeste, Nordeste e Norte.

No ano de 1910, Walle lançou na França sua obra Au Brésil, du Rio São Francisco a L'Amazone (Walle, 1910), resultado de uma das viagens a este país, objetivando estudar as potencialidades comerciais dos diversos estados do Brasil. Inicialmente, embarcou em 1910 na cidade de Vitória (ES), no vapor Acre, do Lloyd Brasileiro, e dali prosseguiu longa viagem. Embora tenha feito referência no título ao rio São Francisco como trajeto de partida, logo no início, em razão de um acidente fatal com um dos membros da expedição (o agrônomo Ernest Dubosc), sua comitiva teve de retornar à costa brasileira e navegar em águas marinhas até a foz do rio Amazonas.

Essa obra de Walle somente foi publicada no Brasil quase cem anos depois, em 2006, momento em que o Senado Federal lançou o livro sob o título No Brasil, do Rio São Francisco ao Amazonas (Walle, 2006), com tradução do diplomata Oswaldo Biato. Interessante notar que há uma variação de sentido entre o título original e o da edição brasileira. Enquanto na edição francesa o autor faz referência direta à Amazônia como região, o título brasileiro traz a dubiedade ao apontar para o rio Amazonas e o estado do Amazonas como pontos de chegadas do viajante.

No subtítulo do referido trabalho temos este texto: "cento e cinco ilustrações e 13 mapas". Porém, não há nenhuma indicação nas versões brasileira e francesa das possíveis autorias das fotografias e dos mapas inseridos em ambas as edições. Walle ou algum outro membro da expedição talvez seja o autor de parte das fotografias e de todos os mapas, que trazem informações descritivas somente em português. Um detalhe é que todas as fotos usadas nessa obra já aparecem em seu livro anterior, Au pays de l'or noir: le caoutchouc du Brésil (Walle, 1911). A edição de 1911 é "segunda", revisada e sem indicação de quando foi publicada a primeira. Outro aspecto obscuro envolve o próprio autor, pois em nenhuma de suas obras encontramos informações sobre sua trajetória pessoal e formação acadêmica - algo que também não consta no site da entidade geográfica francesa da qual ele fez parte.

Além dessa obra, Paul Walle é autor de um livro chamado Do Uruguai ao Rio São Francisco, que antecede o livro que ora analisamos. A partir de $A u$ 
Brésil, du Rio São Francisco a l'Amazone, em 1912, Walle resolveu germinar outras obras, lançadas na França, em partes distintas e separadas umas das outras, remetendo os leitores às suas andanças e impressões de cada uma das unidades federativas brasileiras. Dessa forma, ele se torna autor prolixo, de várias obras no período de apenas um ano. ${ }^{3}$ Sua produção textual pode ser pensada na lógica apontada por Ana Pizarro, segundo a qual essa vasta produção discursiva traz "textos com elementos em comum, cujas relações representam as formas dos imaginários da sociedade europeia em determinadas condições de existência" (Pizarro, 2012, p. 33). Para essa autora, não reside aí um discurso inocente, mas um que procede de "um ponto de vista, de uma história e suas necessidades” (Pizarro, 2012, p. 33).

Walle não traz muitas informações ou impressões pessoais sobre aspectos culturais e políticos dos locais por onde passa. Não é muito dado a elucubrações etnográficas. Centra suas observações mais incisivamente nas questões econômicas, comerciais e industriais, bem como nos recursos naturais que poderiam ser explorados em cada localidade, por empresas francesas privadas ou estatais. E, textualmente, afirma que também quer "examinar os métodos comerciais empregados por nossos concorrentes nesse país" (Walle, 2006, p. 9). Essa assertiva do autor explicita a lógica do colonialismo econômico das potências capitalistas de então sobre esses espaços "atrasados" da chamada periferia global.

Esses viajantes - dos quais Walle é exemplo - ao contrário dos exploradores e naturalistas de períodos anteriores, "não registraram realidades que supunham novas; não se apresentaram como descobridores de um mundo primal" (Pratt, 1999, p. 256). Walle procura com denodo incensar as facilidades econômicas existentes que estariam disponíveis ao ímpeto empreendedor do europeu, bem como os percalços logísticos e de deficiência da mão de obra nesses espaços visitados. São "jornadas que alegorizam o progresso" (Pratt, 1999, p. 257), algo incapaz de se efetivar pelos habitantes locais sempre traduzidos como pertencentes a raças inferiores, preguiçosos, pouco dinâmicos e marcados pelo atraso. São lugares e sujeitos apontados como "retrógados" pelas representações que se fazem deles a partir dos interesses do capital mercantil na "periferia" global, verbalizados por vozes como as de Paul Walle.

O sujeito industrioso, dinâmico, anunciador da modernidade é para ele o europeu, a quem caberia "civilizar" os trópicos. Nessa direção, Walle buscava refutar aqueles que consideravam o norte do Brasil inabitável ao europeu por causa das dificuldades de adaptação e pelo desinteresse em ali investir motivado pelo decantado atraso econômico da região, em função de predominarem 
atividades econômicas extrativas e existirem reiteradas narrativas acerca dos múltiplos signos do "atraso". Afirma então que os estados do Norte têm "má reputação que lhes foi atribuída com base em relatos escritos um pouco levianamente, muito tempo atrás" (Walle, 2006, p. 11). Seu olhar é de incentivo aos potenciais investidores, de positividade em relação à possibilidade de aferição de lucros comerciais em favor dos europeus empreendedores que quisessem investir não região. Ao mesmo tempo se coloca como aquele que redime a região norte do Brasil da "leviandade" lançada por muitos que lhe antecederam.

Especificamente sobre a Amazônia, enfatiza que a região era então muito associada a uma má reputação exagerada de insalubridade. Como forma de se contrapor a essa imagem, diz que, durante sua viagem, encontrou muitos de seus compatriotas "gozando de boa saúde", e que ele mesmo passou ali "três temporadas sem ter tido qualquer enfermidade” (Walle, 2006, p. 11). Não desconhece as doenças endêmicas da região, mas afirma que a malária, por exemplo, atingia, sobretudo, "os indivíduos que abusam de bebidas alcoólicas, ao mesmo tempo que se alimentam de modo insatisfatório” (Walle, 2006, p. 11). Ou seja, a doença era mais um sintoma de degenerescência moral e comportamental dos habitantes locais, mal do qual poderiam ficar imunes os "civilizados" e os modernos homens eurocêntricos adventícios (Walle, 2006, p. 11).

Para reforçar sua tese, Walle indica que muitos europeus estavam bem adaptados ao trabalho na Amazônia, anteriormente vista por vários viajantes estrangeiros e nacionais como inapropriada ao homem "civilizado":

mesmo em regiões tidas como insalubres, como as das margens do rio Madeira, no trecho onde se constrói a estrada de ferro que liga o Madeira ao Mamoré, naquelas florestas onde a movimentação do solo ocasiona a febre do impaludismo, são os operários italianos e espanhóis que fornecem a mão de obra de melhor qualidade. (Walle, 2006, p. 12)

O exemplo da construção da Estrada de Ferro Madeira-Mamoré (EFMM) no atual estado de Rondônia parece ser sintomático na visão de Paul Walle, pelo fato de ser um empreendimento conduzido por norte-americanos e contar com mão de obra essencialmente estrangeira. Entre esses trabalhadores existiam afro-caribenhos, europeus, indianos e de outras nacionalidades não europeias (Hardman, 2005). Contudo, o autor busca destacar a presença de europeus brancos talvez para reforçar sua propaganda comercial, colonialista, e suas crenças eurocêntricas no processo de colonização da Amazônia como uma possibilidade real a quem quisesse investir e ter sucesso, desde que europeu. 
Esse tipo de pensamento não era novidade, pois, algumas décadas antes, o naturalista inglês Alfred Wallace (1979) que viveu por cerca de 4 anos (1848/1852) na Amazônia brasileira, lamentava a natureza pouco explorada frente à ausência de mentalidade empreendedora nos brasileiros, pois esse era um país escravista e mestiço que, naquele momento, sofria pressão da Inglaterra para pôr fim ao tráfico negreiro. Isso gerou à época debates internos no parlamento brasileiro, onde alguns escravistas defendiam o tráfico e o cativeiro dos negros como assunto de soberania nacional, lançando mão de apelos em tons nacionalistas para que se conservassem os interesses do Estado nacional pátrio (Chalhoub, 2012).

Não podemos afirmar se estavam no horizonte de Alfred Wallace essas especificidades envolvendo sua pátria natal e o país escravista onde vivia. Para além disso, inserido na lógica colonial eurocêntrica, ele afirma em tom exagerado e altivo:

quando fico pensando no quanto é fácil transformar esta floresta virgem em verdejantes campinas e produtivas plantações, exigindo-se para tanto uma concentração mínima de trabalhos e esforços, dá até vontade de reunir meia dúzia de amigos entusiasmados e diligentes e vir para cá tirar desta terra tudo que ela nos pode propiciar com fartura. Juntos, mostraríamos à gente do país como seria possível criar aqui um verdadeiro paraíso terrestre a curto prazo, abrindo-lhe os olhos para uma realidade que eles até então jamais conceberam que fosse capaz de existir. (Wallace, 1979, p. 208)

Wallace atribui em tom depreciativo “à gente do país” um caráter de apatia e de falta de iniciativa, de pouco ou nenhum dinamismo empreendedor. Por isso afirma que alguns europeus valeriam mais que muitos brasileiros, pois entre aqueles qualidade e quantidade se conjugavam para fazer mais e melhor com menos braços. Embora não seja direto, esse viajante inglês expressa uma visão do homem branco como superior aos negros, aos indígenas e aos mestiços, que marcavam indelevelmente as populações mais pobres dos "rincões do Brasil” percorridos por ele e, algumas décadas depois, por Paul Walle. Ambos acreditavam piamente no colonizador eurocêntrico como portador do "gosto virtuoso da ação" (Memmi, 1967, p. 78).

Voltando a Paul Walle (2006), suas concepções também racializadas ficam evidentes logo no início de seu texto introdutório, quando atribui o que considera atraso do norte do Brasil à presença negra e à herança escrava do país. Segundo ele, o limitado progresso que haveria na região devia-se ao "número 
exagerado de negros que lá se concentraram após a abolição da escravatura" (Walle, 2006, p. 13). Nominalmente, relaciona os estados da Bahia e do Maranhão como exemplos mais significativos dessa sua visão reducionista e preconceituosa, reforçada ainda mais quando atrela esse decantado atraso às características tropicais e à fertilidade do solo. No âmbito dessa sua concepção, no que tange à possibilidade de desenvolvimento, natureza e "raça" se uniam em um casamento degenerativo prejudicial ao país.

Desse modo, Walle ressalta que diante de um clima suave e da abundância de produtos oferecidos pela natureza, a "vadiagem" e "indolência" de negros e mestiços "prejudicam o desenvolvimento do país" (Walle, 2006, p. 13). Teríamos então uma soma de resultado negativo, onde a exuberância da natureza dadivosa se conjugava com a falta de ação e o "desinteresse atávico" dos mestiços nativos e negros marcados pelo "retrato-acusação da preguiça" (Memmi, 1967, p. 77), que seria uma marca do olhar eurocêntrico desde os momentos inaugurais da colonização do chamado Novo Mundo. Essa natureza negligenciada pelas gentes locais, consideradas inferiores, "tende a ser vista [...] como incômoda ou feia e seu caráter primitivo um sinal do fracasso da audácia humana" (Pratt, 1999, p. 258) porque não é explorada como deveria ser, segundo o olhar colonialista expressado por tantas vozes ao longo dos séculos.

Albert Memmi também alude a essa questão do sujeito coletivo narrado pelo colonizador, tratado genericamente por Paul Walle como 'negros' e 'mestiços', marcas de negatividade. Para o pensador franco-argelino, outra postura comum do colonizador é despersonalizar o colonizado ao carimbá-lo com a "marca do plural" que o "afoga no coletivo anônimo" (Memmi, 1967, p. 81). Assim, na escrita de Paul Walle, são 'os negros' e 'mestiços', 'eles', 'aqueles' e outros termos correlatos que expressam anonimamente e em perspectiva coletiva atemporal os 'males' da raça inferiorizada pelo discurso colonizador. Esse quadro reforça a ideia de abandono e descuido de algumas regiões do país por parte dos “capitalistas, industriais e comerciantes" (Walle, 2006, p. 14), certamente entendidos como europeus. É uma região que ele crê "quase virgem para nossa propaganda comercial e nossa difusão cultural” (Walle, 2006, p. 14). O pronome possessivo da ausência é em relação aos franceses empreendedores, vistos por esse autor como destinados a trazer suas novidades "modernas" ao mundo inferiorizado.

Como um caixeiro-viajante culto e ilustrado, ao passar por Manaus e Belém aponta que "ainda conseguimos vender conservas de todo tipo, vinhos, licores variados e artigos de perfumaria. Mas no que diz respeito a tecidos leves, roupas de cama, tecidos vários e rendas, sofremos a concorrência dos 
produtos belgas" (Walle, 2006, p. 14). Sua descrição ao mesmo tempo que realça a superioridade e o espírito empreendedor do europeu, também apresenta a lógica da competição comercial entre os países colonizadores europeus pelos mercados da periferia global. Há aí configurada a disputa de espaços de influência imperial, de mercados mundiais em expansão que se conectam de maneira desigual e subordinada nas múltiplas hierarquias construídas nas multifacetadas relações entre colonizador e colonizado.

Essa é uma visão duradoura e sempre (re)atualizada em contextos marcados pela lógica do binarismo colonial e "pós-colonial", ${ }^{4}$ como apreendida por Stuart Hall ao abordar essa questão no contexto da segunda metade do século XX:

Problemas de dependência, subdesenvolvimento e marginalização, típicos do "alto" período colonial, persistem no pós-colonial. Contudo, essas relações estão resumidas em uma nova configuração. No passado, eram articuladas como relações desiguais de poder e exploração entre as sociedades colonizadoras e as colonizadas. Atualmente, essas relações são deslocadas e reencenadas como lutas entre forças sociais nativas, como contradições internas e fontes de desestabilização no interior da sociedade descolonizada, ou entre ela e o sistema global como um todo. (Hall, 2003, p. 56)

Nesse diapasão, é possível pontuar que a ênfase atribuída por Walle aos produtos de consumo importados, mais caros e de padrão elitizado, parece querer expressar uma crítica à falta de hábitos cosmopolitas de consumo e bom gosto por parte das elites locais por onde ele passa. Paul Walle demonstra se ressentir por ainda não haver sedimentado nesses espaços de interesses coloniais as "virtudes do conforto, limpeza, eficiência, variedade e gosto" (Pratt, 1999, p. 261), essa mesma crença percebida em outros viajantes que percorreram o continente em períodos anteriores e no coevo.

Seu lado comercial e colonizador, vinculado ao interesse nacional francês, fica bem mais explícito no final da introdução da obra, quando afirma não ter como intuito "fazer qualquer propaganda em favor do Brasil, mas sim permanecer fiel aos interesses da França" (Walle, 2006, p. 14). Explicita-se aí sua honestidade interesseira, sua mentalidade colonizadora e sua lógica do lucro a qualquer custo nas disputas imperiais ainda muito presentes, no início do século XX, nessas regiões ditas periféricas do globo e conduzidas em grande medida pelos Estados europeus mais influentes da época. 


\section{Paul Walle na Amazônia: o olhar colonial ContemporÂneo}

Lançando mão de categorias formuladas por Mary Louise Pratt, Walle pode ser designado como um tipo de batedor avançado do capitalismo europeu, em grande medida, provido de capacidade técnica e formação acadêmica a serviço de investidores privados europeus ou dos seus Estados nacionais. Um tipo de especialista "à procura de recursos exploráveis, contatos e contratos com as elites locais, informações sobre possíveis associações, condições de trabalho, transporte, mercados potenciais e assim por diante" (Pratt, 1999, p. 253). Seguindo a rota de outros viajantes, seus predecessores, Paul Walle palmilha o continente sul-americano - e o Brasil em particular - com o mesmo propósito e olhar portador e agenciador dessa persistente trajetória colonialista do Velho Mundo, que longe de "mistificar os planos expansionistas europeus em seus escritos, tendia a consagrá-los” (Pratt, 1999, p. 255).

Em sua narrativa Walle não aponta as datas de partida e as chegadas aos portos das cidades brasileiras onde vai passando, especialmente em sua viagem pela Amazônia. Ao desembarcar do vapor Acre em Belém, a viagem daí em diante até Manaus ocorre no vapor Alagoas, também de propriedade do Lloyd brasileiro, mas em momento algum ele fala do cotidiano a bordo dos navios em que viajava, interessando-se apenas pelos aspectos externos, situados em terra, que pareciam ser o foco de sua viagem: cidades, seringais, plantações, extração mineral e comércio de importados. O trajeto não era importante: o foco estava nos lugares por onde passava.

Sua permanência em Belém o fez divagar sobre a Amazônia brasileira como um todo, considerando a existência de diversos preconceitos e opiniões desfavoráveis que foram construídos desde os séculos iniciais da conquista e colonização da região. Preconceitos esses presentes até mesmo entre os próprios brasileiros, notadamente, em torno de algumas centralidades que, em sua opinião, pareciam fixadas havia muito tempo: a floresta, os indígenas e a seringueira/caucho. Por contraste, atestou que Belém e Manaus eram as cidades que se prestariam para desconstruir essa visão de senso comum pelo pretenso cosmopolitismo e progresso que exalavam ao estrangeiro ou brasileiro do litoral que ali chegasse (Walle, 2006, p. 293).

"Pará (sic), ou Belém, é sem dúvida a cidade mais importante do Norte e do Nordeste do Brasil" (Walle, 2006, p. 293), assinala o viajante francês. Para justificar tal assertiva, ele considera a capital paraense mais significativa que Salvador, especificamente considerando suas exportações para o exterior e sua beleza arquitetônica, ficando atrás somente de São Paulo e do Rio de Janeiro. 
Descreve a vida comercial e cultural da cidade, seus principais prédios públicos e comerciais, as ruas centrais e os bairros onde moram as pessoas mais abastadas, talvez porque ali residissem aqueles consumidores almejados pelo seu mapeamento comercial, mas também porque a visão desses espaços dava-lhe a comodidade banal dos signos 'civilizados' e burgueses do 'bom gosto' e do 'progresso' que momentaneamente tinha deixado para trás quando saiu da sua França natal.

Uma das instituições visitadas na capital do Pará foi o Museu Emilio Goeldi, onde Walle se encontrou com seu então diretor, o botânico suíço Jacques Huber (1867/1914), e conheceu as coleções de pássaros, ofídios, répteis e botânica ali existentes. Referindo-se à coleção botânica, destaca as plantações experimentais de hevea brasiliensis, ${ }^{5}$ chamada de "árvore do cautchu" e à qual, segundo ele, a Amazônia deve sua prosperidade. Observa ainda haver árvores e mudas de castilloa elastica,${ }^{6}$ "de onde se extrai o produto chamado caucho, tido como pouco inferior ao cautchu [caoutchouc]", e considera o dr. Jacques Huber um estudioso do assunto e entusiasta do cultivo das árvores de látex como a solução para exploração de "modo mais racional" (Walle, 2006, p. 207308) que o tradicional método extrativista predominante na região.

Antes de partir da cidade Paul Walle enfatiza que não queria "deixar Belém sem experimentar o célebre açaî” (Walle, 2006, p. 311), descrevendo o nome científico dessa palmeira e o produto extraído do seu fruto. Em seguida, aborda seu périplo pelas ruas de Belém em busca do suco do açaí, que segundo ele não se encontra nos "bares e cafés decentes" da cidade. Em seu relato, o açaí somente era encontrado em pequenos botequins (estalagens) comerciais identificados por um "morim vermelho" nas suas fachadas. Após entrar em um pequeno estabelecimento e ser servido pelo atendente, descreve suas impressões gastronômicas da seguinte maneira: "líquido xaroposo, espesso, cor de vinho, entre o lilás e o violeta. A célebre bebida, que não se revelava muito atraente à primeira vista, pelo menos para estrangeiros, tinha a aparência de uma emulsão rústica, oleosa, mantendo em suspensão as matérias gordurosas. O sabor é doce e adstringente" (Walle, 2006, p. 311). Em um exercício de descrição sociológica sobre quem aprecia a bebida, aponta que ela era consumida principalmente pelos paraenses que não pertenciam à elite, isto é, pelos mais pobres, que adicionavam farinha de mandioca para aumentar o poder nutritivo e saciar o apetite. Esse seria o motivo pelo qual o açaí seria consumido tão constantemente pelas camadas populares.

Após a saída de Belém, Walle começa a observar a floresta da embarcação na qual se dirige a Manaus. Uma das primeiras impressões é em relação à 
floresta, que ele chama de "virgem" e que forma um "conjunto confuso de vegetação" extremamente denso, onde plantas e árvores "lutam pela vida" e "abafam-se mutuamente" (Walle, 2006, p. 368). Temos aí um duplo olhar colonizador: a virgindade da floresta intocada e a sua ausência de racionalidade explicativa na lógica eurocêntrica, que, desde o início da era moderna, estava impregnada da noção de que a natureza 'aperfeiçoada' pela mão humana trazia as marcas da simetria e da racionalidade, pois esse era o ideal de civilização triunfando sobre a natureza 'inculta' e 'selvagem' (Thomas, 2010).

Paul Walle assevera ainda que o vale amazônico é marcado por um horizonte limitado, composto de três grandezas incomensuráveis: o céu no firmamento, os rios e a floresta no plano horizontal (Walle, 2006, p. 370), marcados pela ausência, pelo infinito e pelo vazio. Parece ele só ver beleza nos espaços domesticados pela mão humana, nas cidades e nas obras humanas marcadas pela "lógica civilizacional" que carrega. Nessa direção, seu pensamento se ancora em uma lógica extrativista modernizadora aliada ao devaneio industrial no qual as matérias-primas deveriam estar disponíveis às indústrias europeias para serem transformadas em produtos que iriam abastecer o mercado global.

Ao chegar a Manaus, Walle sem muito esforço deixa transparecer que seu reencontro com o "mundo civilizado" e urbano se restabeleceu após alguns dias da partida de Belém, transitando por paisagens predominantemente aquáticas e florestais. Embora considere a cidade amazonense inferior a Belém, seus elogios aos espaços arquitetônicos e urbanísticos da capital superam as críticas, tecendo loas aos governantes locais pelas obras e desenvolvimentos realizados na urbe manauara. Assim como aconteceu com sua viagem ao Pará, também no Amazonas não há menções às datas de chegada e saída.

Sobre o Acre, sua narrativa se inicia com referência às querelas com a Bolívia e o Peru, sobre a extensão territorial e suas principais bacias hidrográficas. Aponta que após o Tratado de Petrópolis (1903) o Acre vem passando por "progressos notáveis", com a criação de numerosos estabelecimentos ao longo dos rios para a exploração do cautchu (caoutchouc) (Walle, 2006, p. 408), e alude à divisão administrativa dos Departamentos do Acre Federal. Parece querer fazer um detalhamento da situação da localidade para um público que desconhece essa parte da Amazônia brasileira e fronteiriça que poderia ser de interesse para o estabelecimento de negócios de cunho comercial e financeiro.

Afirma que o "cautchu" é a única indústria existente no Acre Federal, algo que gerava grandes dividendos ao tesouro nacional, sendo esse território suplantado em importância apenas pelos estados de São Paulo e do Rio de Janeiro 
(Walle, 2006, p. 411). Isso teria introjetado nos "proprietários seringueiros" um sentimento de abandono, pela falta de retorno em investimentos por parte do governo federal, que só se beneficiava da riqueza acreana e nada retribuía em investimentos. Aponta que, diante dessa situação, vinha se constituindo entre esses proprietários um desejo de autoadministração, criando um sentimento de autonomia política na localidade.

O autor concorda com a ideia de autonomia acreana, ao dizer que politicamente os governantes deveriam ter mais liberdade de ação nas suas administrações. Contudo, joga essa possibilidade para o futuro, pois assevera que naquele momento ela era inviável, pois "não está provado que a autonomia irá servir realmente aos interesses do estado", e conclui observando que "é preferível que uma parte dos recursos do Acre aproveite a nação, em vez de beneficiar alguns ambiciosos" (Walle, 2006, p. 412), o que parece sugerir desconfiança na elite extrativista/comercial acreana com seus interesses políticos e pessoais na máquina estatal local a ser implantada em caso de autonomia política.

Outro aspecto que reforça as observações descritas anteriormente é a propalada pouca população do Acre, que Walle afirma ser na faixa de 70 mil habitantes. Além da baixa densidade populacional, esses habitantes no olhar do viajante são de "baixa qualidade", pois tomada no seu conjunto essa população "é ignorante e rude, de civilização pouco adiantada". Pessoas que para o autor só viviam ali em função da cobiça gerada pela exploração da borracha e que pouco se importavam com o "destino da região" (Walle, 2006, p. 412).

Uma população inculta de características nômades, diz Paul Walle em seu arremate sobre a questão. Para ele, entregar a soberania a uma sociedade assim seria apostar na anarquia, pois esse tipo de gente ignorante seria facilmente manipulável para os intentos dos poderosos proprietários e patrões do lugar. Pessoas que viviam em armas, frustradas pelas dificuldades do meio e oprimidas pelos fortes (Walle, 2006, p. 413). Essas concepções são muito parecidas com aquelas que o sociólogo Oliveira Vianna vai operar alguns anos depois, ao tratar da situação do Acre como Território Federal e dos anseios de autonomia local, que ele critica de forma veemente no capítulo intitulado "O erro da autonomia acreana”, da obra Pequenos estudos de psychologia social (Oliveira Vianna, 1942), que será publicada pela primeira vez em 1921.

Sobre as questões de salubridade e doenças, Walle destaca que "durante nossas primeiras temporadas na Amazônia, inclusive uma de 6 meses no Madeira e no Purus, e outra atravessando a Amazônia peruana, nunca contraímos qualquer febre palustre" (Walle, 2006, p. 415). A mortandade por doenças 
entre seringueiros, "essa gente ignorante", nos seus dizeres, ocorria por falta de higiene, uso desmedido de bebidas alcoólicas e má alimentação. Uma conjunção perversa de comportamentos e hábitos negativos seriam então os fatores relacionados aos óbitos mais significativos na região.

Sobre os homens que labutavam diretamente na exploração do látex, afirma existirem basicamente dois tipos: os seringueiros e os caucheiros. Os primeiros seriam principalmente originários "dos estados do Nordeste do Brasil, sobretudo habitantes do Ceará” (Walle, 2006, p. 333). Homens esses que ele classifica como "admiravelmente maleáveis, enérgicos e resistentes", que invadiam a "floresta virgem" e se familiarizam rapidamente com a nova existência. Mas assegura que eles não poderiam ser culpados pela rebeldia, ignorância e imprevidência em relação às normas de higiene mais básicas. No âmago desse raciocínio, prevalece a noção de que qualquer europeu civilizado poderia muito bem viver na Amazônia sem os percalços que enfrentam os tradicionais habitantes da região, rotulados como "ignorantes".

Uma das localidades mais insalubres apontadas por Walle é a região do Alto Acre, onde o número elevado de mortes ocorria em razão de uma alimentação baseada em "farinha de mandioca, peixes e carnes secas" (Walle, 2006, p. 415), geralmente deteriorados, como afirma em sua conclusão. Ao analisar as consequências do que considera um tipo ruim de alimentação, enfatiza que o organismo das pessoas ficava fragilizado e propenso a sofrer com risco mortal febres que eram inicialmente de natureza benigna. Mas atesta que, por exemplo, na cidade de Xapuri (AC) essa realidade estava mudando desde as últimas décadas do século XIX. Isso seria fruto da derrubada das florestas no entorno do pequeno povoado para a criação de gado vindo da Bolívia e o cultivo de produtos agrícolas e legumes "que permitiu sensível melhoria na alimentação" da população local da pequena vila acreana. Sobre esse ponto, o viajante entende que o Acre possuía terras que se prestariam "admiravelmente para o plantio de café, milho, arroz, feijão, legumes diversos e frutas tropicais de todas as espécies” (Walle, 2006, p. 415). Também falando sobre o uso comercial e econômico da floresta, ele relata que havia uma infinidade de madeiras aptas a serem utilizadas na construção civil e que a mata fornecia uma profusão de produtos de origem vegetal com ampla aceitação no mercado consumidor final. Cita como exemplos os casos da castanha, do cacau, da copaíba e do quinino. Produtos que não eram valorizados em razão das "vantagens bem mais atraentes oferecidas pela extração do cautchu” (Walle, 2006, p. 416).

Paul Walle também faz um curioso exercício de comparação de preços de alguns produtos comercializados nos altos rios acreanos, convertendo-os para 
a moeda francesa e evidenciando que está interessado em mostrar ao seu leitor na França os preços exorbitantes praticados nos seringais amazônicos do Acre Federal. Se esse público for pensado como formado por comerciantes ligados à Sociedade Geográfica e demais capitalistas franceses interessados em comércio exterior, estes teriam uma indicação de lucros fabulosos que poderiam ser obtidos caso se interessassem em investir capitais para explorar a Amazônia e seu mercado consumidor. Walle alerta ainda que, nessas localidades distantes dos grandes centros da região, era muito comum encontrar produtos adulterados (bebidas) e com prazo de validade vencido (enlatados).

Considera que no Acre os centros mais desenvolvidos são as cidades de Cruzeiro do Sul e Sena Madureira, classificando esta última como a "futura capital do Acre": uma cidade criada em plena "floresta virgem", tendo seu fundador se esforçado "por derrubar uma parte da sombria floresta que cobria todo o terreno", tornando-a uma "cidade moderna de cerca de 4 mil habitantes a contrastar vivamente com a natureza circundante" (Walle, 2006, p. 422). Os velhos paradigmas dualistas e em eterna oposição são colocados em evidência: urbano/rural; cidade/floresta; civilização/barbárie e cultura versus natureza, para operarem hierarquias e separações entre mundos distintos.

Sobre a região do Juruá, onde está situada a cidade de Cruzeiro do Sul, considera uma área promissora ao desenvolvimento tendo como base a exploração do "cautchu". Entre os tipos humanos ali presentes, realça a figura do regatão. No texto em francês ele não traduz essa palavra, mas explica no complemento que é uma espécie de "mascate ambulante" que vende mercadorias variadas e desagrada sobremaneira os "patrões seringueiros". Em sua definição, os regatões eram homens que penetravam nas regiões mais distantes da Amazônia e de suas gentes, "para as quais trazem com o comércio um pouco de civilização", sendo que "os índios pacificados esperam com impaciência as suas aparições de quando em quando" (Walle, 2006, p. 427). Consumo e civilização aqui são complementos que se encerram.

Os indígenas merecem atenção especial do viajante francês, que os classifica nas categorias de bravos ou selvagens e mais ou menos civilizados. Os que já tiveram contato com os "brancos"/colonizadores, diz ele, são extremamente úteis como remadores e mateiros. Quando busca criar padrões de características generalizantes sobre os indígenas, afirma que eles só querem viver em paz, mas muitas vezes se reúnem em bandos para atacar vingativamente "propriedades, expedições ou grupos de seringueiros", e sintetiza o que chama, genericamente, de índio brasileiro: "vingativo, e muitas vezes cruel, na verdade 
ele é principalmente cabreiro [méfiant/desconfiado], e raramente provoca conflitos, dos quais sairá sempre vencido, e sua tribo dizimada, levando ódio no coração e uma sede ainda mais viva de vingança" (Walle, 2006, p. 428). Sobre o perfil dos "brancos" que conflitavam com os indígenas, destaca que a maioria deles - mesmos os mais honestos - desprezam e consideram os indígenas inferiores, pouco acima dos animais.

Diante desse quadro, o viajante aponta pretensos gestos humanitários de proteção e benevolência da parte do governo brasileiro que, por intermédio da Igreja católica, propiciava que seus missionários tentassem trazer os indígenas da região "para um grau de relativa civilização" (Walle, 2006, p. 429), mas lamenta o pouco número de agentes do Estado e de religiosos para esse tipo de trabalho. E diz que não se pode acreditar que algum dia todos os indígenas "se elevarão ao nível da população civilizada”, mas gradualmente se tornarão agricultores e criadores de gado, mesmo que não se sintam culturalmente dispostos ao que define como trabalho assíduo:

Seria curioso e belo, e ousamos depositar nossas esperanças nesse sentido, ver os últimos aborígines, os descendentes dos altivos tupinambás, se associarem aos descendentes dos rudes conquistadores que, partindo do litoral, os expulsaram pouco a pouco para as florestas amazônicas, a fim de, todos juntos, valorizarem as riquezas incontáveis e inesgotáveis de uma das mais ricas regiões do globo. (Walle, 2006, p. 431)

Il serait curieux et beau, et nous n'osons y croire, de voir les derniers aborigènes, les descendants des fiers Tupinambas, s'associer aux descendants des rudes conquérants qui, du littoral, les refoulèrent peu â peu vers les forêts amazoniennes, pour mettre ensemble en valeur les richesses innombrables et inépuisables d'une des plus riches contrées du globe. (Walle, 1912, p. 78)

Aparecem aqui as noções de que os indígenas deveriam ser assimilados nas lógicas de trabalho, cultura e valores dos conquistadores, do Estado nacional e outras instituições, como a Igreja. Os povos indígenas não são vistos como seres culturais e humanos completos, mas, seres imperfeitos que poderiam ser úteis nos projetos de conquista e colonização defendidos como únicos modelos válidos pelo autor. Trata-se de uma concepção que Mary Louise Pratt denominou de crença em um "corpo sem discursos, biologizado com a força de trabalho desenraizada, despojada e disponível, que os colonialistas europeus lutaram para criar" (Pratt, 1999, p. 101). É a narrativa do que está disponível 
e do que pode ser aperfeiçoado na perspectiva eurocêntrica de mundo, ainda tão presente nos dias de hoje.

Para finalizar, consideramos importante observar que, na tradução da obra de Walle, do francês para o português, há uma significativa presença de 'atualizações', 'supressões' e 'correções' feitas pelo tradutor, conforme podemos perceber no trecho descrito a seguir, em que a expressão "nordeste" é inserida para dar familiaridade ao leitor de hoje. Suprimem-se as referências aos estados da Bahia e de Minas, por talvez entender o tradutor ter havido uma imprecisão do autor francófono. E por fim, a correção na quantidade de deslocados para a Amazônia acreana é "atualizada" para entre "20 mil e 30 mil” na edição brasileira, algo distinto do texto original:

Les hommes se recrutent principalement entre les immigrants des États de Ceara, de Bahia et même de Minas Geraes; mais ce sont principalement les immigrants de l'État de Ceara, auxquels on donne le nom de Paroaras, qui fournissent le plus grand nombre de bras à l'industrie du caoutchouc. Il en arrive plus de 20.000, chaque année, qui se dispersent avec leur famille dans les diverses parties de l'Amazonie. Admirablement souples, énergiques et endurants, ils envahissent la forêt vierge; ils se familiarisent en peu de temps avec les nécessités de leur nouvelle existence. (Walle, 1911, p. 150)

Evidentemente, a subjetividade do tradutor e os interesses oficiais no contexto da edição brasileira de 2006 atuam nesse percurso (re)criativo, no momento de transladar o relato de viagem para a língua portuguesa (brasileira). Não podemos deixar de reconhecer, no entanto, que a tradução da obra de Walle - como qualquer outra tradução - traz significativas diferenças em relação ao texto original, embora as ideias gerais do autor, suas leituras sobre a região que visita e suas gentes sejam correspondentes em ambos os textos.

\section{CONSIDERAÇÕES FINAIS}

Em nossa percepção, o escritor e viajante Paul Walle se enquadra no rol daqueles que compreendiam o mundo a partir de uma "consciência planetária eurocêntrica" (Pratt, 1999), que teria se estabelecido a partir do século XVIII em relação ao mundo natural (plantas, animais, recursos naturais), com significativos registros em relatos de viagens de europeus aos continentes africano e americano na segunda metade do século XVIII e início do XIX. A narrativa 
do outro geográfico incorpora de forma subordinada essas regiões do mundo pela lógica linear do progresso eurocêntrico, em que "as múltiplas culturas do mundo são marcadas, não positivamente pelo que as distingue, mas por uma relação retrospectiva subordinada em relação ao tempo linear europeu" (McClintock, 2010, p. 30).

Walle era uma autoridade letrada, livresca, autor caudaloso sobre a região, apontado em alguns jornais brasileiros como propagandista da borracha amazônica, cientista e homem de Estado. Encarnava em uma só pessoa as marcas mais explícitas de um estrangeiro culto e de palavras carregadas de autoridade, e, nessa condição ou desde esse lugar de fala, a Amazônia que narra não é comercial e culturalmente afrancesada, faltando-lhe um comércio e a migração de homens de negócios estabelecidos que pudessem rivalizar ou suplantar a influência comercial da Inglaterra.

Sua narrativa é tanto de exploração como de viagem. Transita nas zonas de contatos levando seus pontos de vistas e seus conhecimentos numa perspectiva de superioridade moral, ética, científica e racial. Nos seus relatos não há aspectos de fundo sensacionalista ou fantástico, anedótico ou fantasioso, posto que seu foco é a preocupação em tudo racionalizar, tornar crível e abalizado: tudo se credita como real, não como imaginário.

As imagens fotográficas e os mapas de seu relato, mesmo com a ausência de autoria, buscam conferir autenticidade e objetividade às narrativas escritas. Com os mapas, temos "tecnologias da posse e do conhecimento que visam capturar um lugar de maneira cientifica” (McClintock, 2010, p. 53), quando procura cartografar visualmente a região e mostrar os caminhos que levam aos seus interiores. São cartas de acessibilidades que, em conjunto com as fotografias, tentam apresentar suas gentes, modos de vida, suas potencialidades e as possíveis oportunidades de negócios aos empreendedores de fora, que poderiam vir explorar a região. Na lógica de Walle, são essas potencialidades que tornam as descrições e as imagens relevantes, pois não se trata de meras ilustrações gratuitas para deleite estético do exótico.

Em síntese, o que temos é o relato de um homem metropolitano ilustrado, ligado ao colonialismo e voltado para os interesses dos colonizadores potenciais e ao futuro comercial de uma nação europeia, em particular, e dos impérios europeus em geral. Walle é alguém que realça e almeja com um futuro radioso o aprofundamento dessas relações assimétricas e hierárquicas nas outras partes do mundo tornado global e profundamente desigual. 


\section{REFERÊNCIAS}

ALBUQUERQUE, Gerson R. de. Amazonialismo [verbete]. In: ALBUQUERQUE, Gerson R. de; SARRAF-PACHECO, Agenor. Uwa’kürü: dicionário analítico. v. 1. Rio Branco: Nepan, 2016. p. 73-96.

BATISTA, Djalma. O complexo da Amazônia: análise do processo de desenvolvimento. 2. ed. Manaus: Valer, 2007.

CHALHOUB, Sidney. A força da escravidão: ilegalidade e costume no Brasil oitocentista. São Paulo: Companhia das Letras, 2012.

HALL, Stuart. Da diáspora: identidades e mediações culturais. Tradução: Adelaine la Guardia Resende et al. Belo Horizonte: Ed. UFMG, 2003.

HARDMAN, Francisco Foot. Trem-fantasma: a Madeira-Mamoré e a modernidade na selva. São Paulo: Companhia das Letras, 2005.

KIENING, Christian. O sujeito selvagem: pequena poética do Novo Mundo. Tradução: Silvia Nauroski. São Paulo: Edusp, 2014.

MCCLINTOCK, Anne. Couro imperial: raça, gênero e sexualidade no embate colonial. Tradução: Plínio Dentzien. Campinas: Ed. Unicamp, 2010.

MIGNOLO, Walter D. La Idea de América Latina: la herida colonial y la opcion decolonial. Traducción: Silvia Jawerbaum y Julieta Barba. Barcelona: Gedisa, 2007.

MEMMI, Albert. Retrato do colonizado precedido pelo retrato do colonizador. Tradução: Roland Corbisier e Mariza Pinto Coelho. Rio de Janeiro: Paz e Terra, 1967.

OLIVEIRA VIANNA, Francisco. O erro da autonomia acreana. In: OLIVEIRA VIANNA, Francisco. Pequenos estudos de psychologia social. 3. ed. Rio de Janeiro: Cia. Ed. Nacional, 1942. p. 143-155.

PIZARRO, Ana. Amazônia: as vozes do rio: imaginário e modernização. Tradução: Rômulo Monte Alto. Belo Horizonte: Ed. UFMG, 2012.

PRATT, Mary Louise. Os olhos do império: relatos de viagem e transculturação. Tradução: Jézio Hernani Bonfim Gutierre. Bauru: Edusc, 1999.

THOMAS, Keith. O homem e o mundo natural: mudanças de atitudes em relação às plantas e aos animais (1500-1900). São Paulo: Companhia das Letras, 2010.

TODOROV, Tzvetan. A conquista da América: a questão do outro. Tradução: Beatriz Perrone Moisés. São Paulo: Martins Fontes, 2014.

WALLACE, Alfred Russel. Viagens pelo Amazonas e rio Negro. Tradução: Eugênio Amado. São Paulo: Edusp, 1979.

WALLE, Paul. No Brasil, do Rio São Francisco ao Amazonas. Tradução: Oswaldo Biato. Brasília: Senado Federal, 2006.

WALLE, Paul. Au Brésil, du Rio São Francisco a L’Amazone. Paris: Libraire Orientale \& Americane, 1910.

WALLE, Paul. Au Brésil: État D’Amazonas et Territoire Fédéral de L'Acre. Paris: Libraire Orientale \& Americane, 1912. Fonte: Bibliotheque numerique Caraibe 
Amazonie Plateau des Guyanes. Disponível em: www.manioc.org. Acesso em: 23 ago. 2017.

WALLE, Paul. Au pays de l'or noir: le caoutchouc du Bresil. Paris: Libraire Orientale \& Americane, 1911. Fonte: Bibliotheque numerique Caraibe Amazonie Plateau des Guyanes. Disponível em: www.manioc.org. Acesso em: 23 ago. 2017.

\section{NOTAS}

${ }^{1}$ Novo Mundo, América Latina e Amazônia são categorias complexas e polissêmicas. Entendemos esses termos como carregados de particularidades históricas e conceituais que os aproximam e os distanciam. Dados os objetivos traçados no presente artigo que limitam tal discussão, apontamos algumas obras que discutem com mais acuidade essas significâncias: uma análise estética e discursiva sobre a emergência do termo "Novo Mundo" pode ser aprofundada na obra de Christian Kiening (2014), sobretudo na primeira parte, intitulada "Novo Mundo imaginário". Tzvetan Todorov (2014) e Walter Mignolo (2007) trazem em suas respectivas obras abordagens mais detalhadas sobre o termo América Latina no contexto colonial e decolonial. Para um trânsito sobre os sentidos históricos, as representações construídas sobre a Amazônia/Pan-Amazônia e uma ampla bibliografia de autores que lidam com esse termo, ver o verbete "Amazonialismo" (ALBUQUERQUE, 2016).

${ }^{2}$ Existe atualmente uma vasta produção bibliográfica que faz uso do termo "Pan-Amazônia" com seus múltiplos significados. Contudo, encontramos em obra de Djalma Batista lançada em 1976 o uso mais recuado e detalhado do termo, que o autor entende sobretudo por sua dimensão geográfica e espacial. Batista atribui a criação do termo ao médico Gastão Cruls nos anos 1950 (BATISTA, 2007).

${ }^{3}$ Todas as obras estão disponíveis em Hathi Trust Library (https://goo.gl/M8AxBM). Acesso em: 18 ago. 2017.

${ }^{4} \mathrm{O}$ termo "pós-colonial" é colocado em destaque para realçar seu problema conceitual conforme destacado por McClintock (2010), ao dizer que: "o termo 'pós-colonialismo' marca a história como uma série de estágios ao longo do memorável caminho do 'pré-colonial' ao 'colonial' - um compromisso espontâneo, ainda que negado, como o tempo linear e com a ideia de desenvolvimento" (MCCLINTOCK, 2010, p. 29).

${ }^{5}$ Planta da família da Euphorbiaceae e de nome popular Seringueira. Nativa das áreas tropicais da Pan-Amazônia. Fonte: Instituto de Pesquisas e Estudos Florestais (Ipef). Disponível em: https://bit.ly/2pj9Z6R. Acesso em: 15 set. 2018.

${ }^{6}$ Planta da família das Moraceae, nativa da América Central (onde é chamada de Mexican Rubber tree/Panama Rubber) e parte da América do Sul. Fonte: Biosecurity Queensland Edition. Disponível em: https://bit.ly/2MCLafh. Acesso em: 15 set. 2018. 